\title{
AS TRANSFORMAÇÕES DO COURO NO TRABALHO DE ESPEDITO SELEIRO COMO ALTERNATIVA DE SUPERAÇÃO PARA AS ADVERSIDADES DO SERTÃO.
}

\section{CHANGING OF THE LEATHER WORK ESPEDITO SELEIRO AS ALTERNATIVE FOR OVERCOMING THE ADVERSITIES OF SERTÃO.}

\author{
Valeska Alecsandra de Souza Zuim ${ }^{1}$ \\ Ana Cláudia Silva Farias ${ }^{2}$ \\ Ana Fabiola Pedrosa de Vasconcelos ${ }^{3}$ \\ Maria Silvia Barros de Held 4 \\ Antonio Takao Kanamaru ${ }^{5}$
}

\section{RESUMO}

Este artigo tem por objetivo inicial incentivar a reflexão acerca das adversidades encontradas nos sertões nordestinos por causa da seca e como a matéria - prima couro teve importância na colonização do nordeste e vida dos vaqueiros e artesões locais. Apresenta também como o trabalho com 0 couro do mestre artesão Espedito Seleiro o auxiliou na superação das dificuldades de se viver no Sertão nordestino. E como esse mesmo couro mudou a realidade dos moradores da cidade de Nova Olinda no Sertão do Ceará.

Palavras - chaves: Sertão - Couro - Artesanato - Espedito Seleiro Renovação.

\section{ABSTRACT}

This article has the initial objective to encourage reflection about adversity found in the northeastern hinterlands because of drought and as matter - press leather had a role in colonization of the northeast and life of cowboys and local artisans. Also shows how the work with the leather master craftsman Espedito Seleiro had helped him overcome the difficulties of living in the Northeast. And as this same leather changed the reality of the residents of the city of Olinda in the backlands of Ceará.

Keywords: Sertão - Leather - Craft - Espedito Seleiro - Renewal. 


\section{INTRODUÇÃO}

Atualmente o trabalho informal anda ganhando cada vez mais adeptos na realidade brasileira. Índices do IBGE ${ }^{6}$ indicam que em 2012, 42,2 milhões de pessoas, em torno de $22 \%$ do total da população brasileira, estimada em cerca de 193 milhões, tem algum tipo de trabalho desvinculado a qualquer empresa.

A concentração dos trabalhos gira em torno de serviços de reparo, na diversão domiciliar, na construção civil e na indústria de confecção e artesanato.

O artesanato, área de concentração desse artigo, é um ramo que dispensa maquinários complexos e concentra-se na manufatura de objetos diversos com os mais vários fins. Neste ofício, os artesãos têm total domínio de todas as etapas dos processos de fabricação dos produtos.

Ainda de acordo com o IBGE em pesquisa realizada em parceria com o Ministério da Cultura no ano de 2012, 64,3\% dos municípios brasileiros possuem algum tipo de produção artesanal. Essa produção tem grande importância na geração de ocupação e renda no Brasil, em que milhões de artesãos são responsáveis por um movimento financeiro que comprova a capacidade econômica desse setor.

Diante do exposto, este artigo visa contar um pouco da experiência de um dos mestres artesãos do couro do Ceará, que venceu as dificuldades se se tornar um artesão em meio as adversidades do sertão, promovendo renda e visibilidade para seu trabalho e localidade em que mora.

O artesão Espedito Seleiro tem 74 anos e mora em Nova Olinda, região sul do Ceará, sertão do Cariri. Sempre trabalhou com o 'couro' como seu pai e avô. Com oito anos começou a aprender o oficio de seleiro ${ }^{7}$ e até hoje nunca desejou mudar de profissão. No início fazia peças tradicionais como seu pai, entretanto, enfrentou muitas dificuldades em vender os produtos para sustentar a família, devido às consequências das secas no sertão do Ceará. Com habilidade, criatividade, perseverança, coragem e uma ajudinha do destino, o artesão mudou o estilo do que estava produzindo gerando visibilidade, renda e reconhecimento para seu trabalho. 
Este artigo inicialmente mostrará um breve histórico das adversidades e dificuldades encontradas pelos personagens da seca nos sertões nordestinos, para, em seguida, apresentar como o trabalho com 0 couro, matéria-prima do artesão Espedito Seleiro, teve importância na colonização do Nordeste. Além disso, nos debruçaremos brevemente sobre a figura do vaqueiro como peça-chave dessa colonização e principal fonte de inspiração do mestre artesão Espedito Seleiro. Na última parte do artigo traremos dados que mostram como o trabalho com o couro fez com que 0 referido artesão superasse as dificuldades enfrentadas no sertão nordestino e trouxesse uma nova realidade para ele e os demais trabalhadores da região que sobrevivem do couro.

\title{
AS ADVERSIDADES DA SECA NOS SERTÕES NORDESTINOS
}

Sobre a realidade das secas no Nordeste, o ex-senador da República Lúcio Alcântara (1995 - 2003), em texto para apresentação do livro de Marco Antônio Villa: "Vida e Morte no Sertão" (2000, p. 7-9), relata:

\begin{abstract}
Fui testemunha em 1984 do sofrimento do povo cearense, em que a economia sertaneja estava esgotada. E não havia mais recursos para manter os milhões de sertanejos sem ocupação fixa. A gravidade da estiagem atingia todo o Nordeste. Eram mais de mil municípios afetados pelo flagelo, todos exauridos, resistindo bravamente a cinco anos contínuos de seca.
\end{abstract}

Citando o levantamento de Villa (2000), este artigo traz inicialmente um resumo dos dados históricos feito por este autor sobre as secas vivenciadas no nordeste desde 1552, como embasamento para o entendimento desta realidade do povo nordestino. Ele mostra que o drama das secas tem uma longa história, em que o primeiro registro da ocorrência de seca é de 1552, três anos após a chegada do primeiro governador geral, Tomé de Souza.

Depois em 1583, as fazendas de canaviais e mandioca secaram e a fome se alastrou, obrigando entre 4 ou 5 mil índios a migrarem para outras regiões. Com a ocupação holandesa em meados do século XVII, teve início de forma mais enfática a ocupação do Sertão nordestino, por meio da pecuária. Carne e leite havia em abundância, mas o restante não. Em seguida houve 
seis grandes secas: 1603, 1605 - 1607, 1614, 1645, 1652 e 1692 que afetaram principalmente a Paraíba, Rio Grande do Norte e o Ceará.

No século XVIII ocorreram mais sete grandes secas: $1710-1711$, 1721, 1723 - 1727, 1736 - 1737, 1745 - 1746, 1777 - 1778, 1791 - 1793, com efeitos ainda mais devastadores, devido ao crescimento da população vinculada a pecuária, que trouxe desastrosos efeitos econômicos, com o deslocamento das populações para as áreas menos afetadas pelo flagelo e 0 surgimento de pequenos grupos de bandoleiros, que acabaram marcando durante mais de dois séculos a história da região.

Entre 1824 - 1825, o Sertão foi acometido por outra grande seca. Nesta época agravaram-se as precárias condições de vida dos sertanejos com o banditismo que se espalhou por toda a região. Em 1845 novamente outra grande seca atingiu boa parte do nordeste. Entre 1877 - 1879, a seca se intensifica e parte da população migra do sertão para o litoral, gerou uma aglomeração de indivíduos que casou o desenvolvimento de diversas moléstias de um modo epidêmico. Neste período, muitos trabalhadores foram forçados a migrar para a Amazônia, em busca das riquezas da borracha. Em 1906, Rodrigues Alves enfatizou a necessidade de obras como a construção de açudes, abertura de poços e estradas de ferro, além da criação da Superintendência de Estudos e Obras Contra os Efeitos das Secas, hoje atual Departamento Nacional de Obras Contra as Secas - DNOCS. Após mais uma seca em 1915, tudo começou a voltar ao "normal" na região, com o retorno paulatino e irregular das chuvas, os retirantes ${ }^{8}$ aos poucos voltaram aos seus lares.

A fim de amenizar os efeitos da seca de 1915, o governo distribuiu sementes para os agricultores pobres cultivarem, mas o plantio foi feito de forma precária e as chuvas não foram suficientes para a obtenção de uma boa colheita. Com as previsões de chuvas para a região Nordeste neste período, o governo federal interrompeu a ajuda aos camponeses que haviam migrado para as cidades e vários governos estaduais obrigaram a população a voltar para o sertão.

Entre 1931 - 1932, mais uma seca se alastra pelo Nordeste, sendo decretado calamidade pública nos sertões do Ceará, Paraíba, Rio Grande do 
Norte, Pernambuco, Piauí, Alagoas e Sergipe. Os comércios paralisaram, não havia sinal algum de chuva e o calor chegava a 38 graus na sombra.

Em 1970 a falta de chuvas anunciava mais uma seca, flagelados saqueavam as feiras das cidades e o aumento do fluxo migratório acabou gerando manifestações de discriminação contra os nordestinos. De acordo com os projetos do governo, entre 1976 e 1979 deveriam ser irrigados 84,6 mil hectares, mas até 1983 tinham sido irrigados somente 13,3 mil hectares. O programa atendeu a $3,8 \%$ da população da região. O programa não redistribuiu renda e nem gerou aumento de produção e da produtividade entre os agricultores. Por outro lado, a migração para outras regiões, especialmente o Sudeste, não parou de crescer. Se em 1970, o saldo negativo migratório era de $3.472,958$, saltou para $5.495,612$ em 1980 , vindos principalmente da região semiárida.

Pontes (1979, p. 24), também descreve um pouco da realidade vivida no Sertão:

\begin{abstract}
Quando a chuva tarda, o povo definha, humilha-se e se torna mais pesaroso, mas não se acovarda, não se abate no ânimo; continua a luta contra a natureza, valendo-se dos santos mais milagrosos, aos quais suplica o advento da invernada. Clama por água e quando o trovão ribomba, é como telegrama da chuva que não tarda. O inverno pegado, eis que se abre um mundo de felicidade, que passa a solver com antecipação as necessidades por maiores que sejam. Época de colheita, tempo de fartura, bonança, prosperidade, conciliando alegria, alvoroço, trabalho e prazer, contaminando as populações em festa.
\end{abstract}

Em 1984 a Sudene decidiu que o enfoque principal do programa seria dado à execução de obras públicas voltadas para o fortalecimento da infraestrutura hídrica, enfatizando o emprego da maior parte da mão-de-obra ociosa em decorrência da seca. No mesmo período chuvas acontecidas na região, levaram novamente o governo a paulatinamente diminuir os recursos das frentes de emergência até desativá-las.

Ainda segundo Villa (2000, p. 250):

É evidente que as constantes secas debilitaram a economia nordestina e aprofundaram o fosso que separa a região das áreas mais desenvolvidas do país. A transformação do Nordeste em região - problema, não só afastou investimentos estrangeiros, mas, fez com 
que as politicas econômicas dos governos republicanos transferissem recursos para o Centro Sul, tendo sempre uma boa justificativa.

Ainda hoje o Nordeste vive fases de seca em alguns estados, mesmo com os programas atuais do governo para combate da mesma. Muitos sertanejos sofrem a falta d'água, sendo obrigados a andar quilômetros para pegar baldes em açudes quase vazios ou esperar os carros pipas.

\section{A TRADIÇÃO DO ARTESANATO COM O COURO}

O couro possui atributos de versatilidade, durabilidade e história que servem de diferenciais para concepção de um produto. A prática de curtimento do couro é uma atividade que vem acompanhando a humanidade desde a préhistória. Conta Laver (2001), que as peles de animais eram usadas para se protegerem das condições climáticas e como diferenciação social pelas primeiras civilizações, sendo curtidas por eles pela mastigação e salivação no intuito de deixarem maleáveis.

$\mathrm{Na}$ história encontram-se registros de civilizações como o Egito antigo, China, Babilônios, Hebreus, Árabes, que desenvolviam processos de curtimento artesanais e fabricavam objetos de couro, como elmos, escudos, calçados e gibões.

No Brasil, com a colonização os rebanhos de gado se multiplicaram rapidamente, tomando conta da costa litorânea do país. Assim, para que as lavouras de cana-de-açúcar pudessem ficar livres, o gado era levado para ser criado longe. Por esse motivo, o couro teve grande influência na economia cearense, uma vez que segundo Couto Filho (2000), na época da colonização do território brasileiro, especificamente do Nordeste, o Ceará situava-se como entreposto entre as capitanias produtoras de açúcar e era caminho para a passagem do gado em direção às outras áreas do Nordeste que não tinham vocação para o plantio de cana-de-açúcar.

Dentro desse cenário de desbravamento do Nordeste, encontrava-se um personagem que foi fundamental para o desenvolvimento local. Esse personagem foi o 'vaqueiro', que munido da ponta do ferrão, vestido dos pés a cabeça de roupa de couro, mugia a boiada, desbravando o Sertão. 
Hoje o vaqueiro é figura presente nos interiores e fazendas de gado do nordeste. Entretanto, a quantidade desses trabalhadores é indiscutivelmente menor do que no inicio da colonização. Mesmo assim, continuam usando o couro na composição de sua roupa do dia a dia e acessórios de trabalho. O couro juntamente com o vaqueiro tornaram-se tradições nordestinas, ambos sempre juntos, unidos pela tradição familiar. Além do vaqueiro, o couro faz parte da tradição cultural e do cotidiano de milhares de nordestinos, sendo matéria-prima para o desenvolvimento de artefatos artesanais diversos, como a produção de chapéus, calçados, bolsas, móveis, esculturas, dentre outros, cujas técnicas são passadas de pai para filho. As principais cidades do Ceará no artesanato coureiro são Juazeiro do Norte, Morada Nova, Assaré, Jaguaribe e Crato.

Euclides da Cunha em sua clássica obra 'Os Sertões' (1984), descreve bem o vaqueiro das Caatingas:

\begin{abstract}
"O seu aspecto recorda, vagamente, à primeira vista, o do guerreiro antigo exausto da refrega. As vestes são uma armadura. Envolto no gibão de couro curtido, de bode ou de vaqueta; apertado no colete também de couro; calçando as perneiras, de couro curtido ainda, muito justas, cosidas às pernas e subindo até às virilhas, articuladas em joelheiras de sola, e resguardados os pés e as mãos pelas luvas e guarda-pés de veado - é como a forma grosseira de um campeador medieval desgarrado em nosso tempo. Esta armadura, porém, de um vermelho pardo, como se fosse de bronze flexível, não tem cintilações, não rebrilha ferida pelo sol. É fosca e poenta. Envolve ao combatente de uma batalha sem vitórias... A sela da montaria, feita por ele mesmo, imita o lombilho rio-grandense, mas é mais curta e cavada, sem os apetrechos luxuosos daquele. São acessórios uma manta de pele de bode, um couro resistente cobrindo as ancas do animal, peirorais que Ihes resguardam 0 peito, $e$ as joelheiras apresilhadas à juntas. Este equipamento do homem e do cavalo talha-se à feição do meio. Vestidos doutro modo não romperiam, incólumes, as caatingas e os pedregais cortantes" (CUNHA, 1984, p. 118-119).
\end{abstract}

Abaixo na figura 1, encontram-se a foto do traje tradicional desse homem guerreiro do Sertão, feito pelos artesões do couro e fotografado por Andreas Heiniger no período de 2001 a 2007, em exposição acontecida em 2009 no Pavilhão da Bienal no Ibirapuera em São Paulo, com o tema "Vaqueiros". 
Figura 1: Foto da exposição "Vaqueiros” (2009), por Andreas Heiniger.

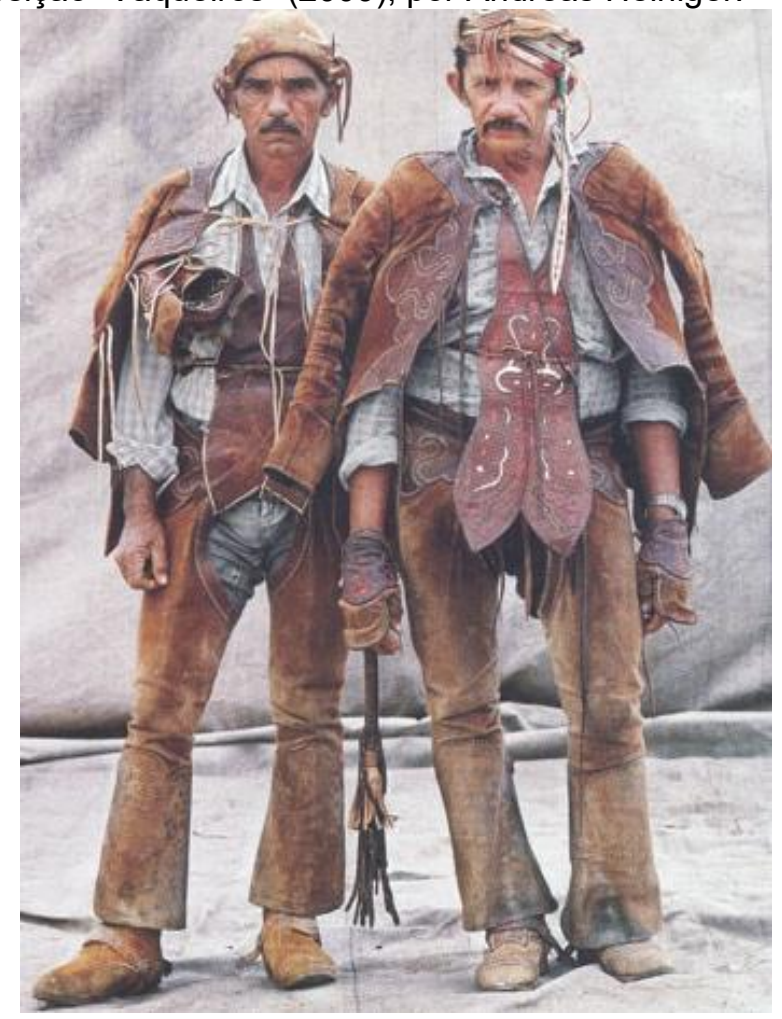

Fonte: http://www.modasemfrescura.com.br/tag/vaqueiros/

Como Euclides da Cunha desenha em palavras tão bem, as vestes dos vaqueiros, parecem armaduras ou couraça, caracterizadas principalmente em couro cru, com cor suja de ferrugem, devido aos processos de curtimento primários. O traje completo sempre foi todo feito artesanalmente pelos seleiros artistas do couro. Com pespontos e amarrações de cordões, trabalham peças como gibão, peitoral, perneiras, luvas, jaleco e chapéu. O gibão é enfeitado com pespontos e fechado com cordões de couro. O peitoral é preso por uma alça que passa pelo pescoço. As perneiras que cobrem as pernas do pé até a virilha são presas na cintura para que o corpo fique livre para cavalgar. As luvas cobrem as costas das mãos, deixando os dedos livres. Nos pés usam botinas ou alpercatas. $\mathrm{O}$ jaleco feito de couro de carneiro, usado geralmente em festas, tem dois lados diferentes: um para o gélido da noite, com a lã e o outro com o couro liso para o calor do dia. O chapéu tem a forma muito baixa e com abas curtas, protegendo o vaqueiro do sol e dos golpes dos espinhos e galhos da caatinga e, às vezes, curiosamente, sua copa é usada para beber água ou comer. 
O trabalho do vaqueiro é muito duro e constante, ele deve estar sempre alerta, vigiando e guardando a fazenda ou região para que foi destinado. Alguns mais habilidosos, além de vaqueiros são seleiros e com pericia cortam e produzem as roupas e acessórios para os vaqueiros. O $\mathrm{Sr}$. Antônio Seleiro era um deles, simples, humilde, nasceu em Campos Sales interior do Ceará e ensinou desde cedo ao seu filho Espedito o oficio de Seleiro e vaqueiro.

Quando faleceu em 1971, seu filho Espedito assumiu os negócios do pai, ressaltando mais uma vez a tradição familiar. Entretanto, preferiu ficar só com a profissão de seleiro, continuando a fabricação das peças em couro e com elas, sustentando seus irmãos e mãe, já que era o filho mais velho. Assim ainda rapaz, cujo nome é Espedito Veloso de Carvalho, ficou conhecido como Espedito Seleiro por fazer selas para os vaqueiros como seu pai e levando adiante mais um exemplo de tradição familiar.

\section{RENOVAÇÃO NA TRADIÇÃO DO ARTESANATO COM O COURO: O trabalho com o couro de Espedito Seleiro superando as adversidades do Sertão}

No Sertão ainda encontram-se famílias que mesmo em segmentos diferentes como a madeira, a palha, o barro, o gesso, as rendas, seguem a perspectiva da tradição e o ofício é passado de geração a geração, entretanto, a cada uma, encontra-se uma realidade artesanal com diversas particularidades. Alegre (1994, p. 66), apoia dizendo que "mesmo quando o artista ultrapassa as fronteiras familiares e inclusive as barreiras de sua origem social, percorrendo outros caminhos e sofrendo outras influências, o peso da iniciação na família permanece por toda a vida".

Essa definição de Alegre (1994) não sugeriu que o artesanato deva ser engessado em uma categoria homogênea, como muitos acreditam. Ele pode seguir culturalmente uma tradição familiar, mas sofre interferências no percurso de cada geração com o ganho de conhecimentos e a renovação do processo produtivo. Como exemplo, continua-se citando o mestre artesão Espedito Seleiro. Atualmente com 74 anos, vive em Nova Olinda, Sertão do Cariri. Mudou-se de Campo Sales logo depois que seu pai morreu. Tem seis 
filhos e todos eles com mais os agregados aprenderam e trabalham com o oficio do couro, auxiliando em sua oficina.

Seu trabalho de artesão tem uma base construída na perspectiva da tradição, onde no início era uma continuação do que fazia seu pai, que por sua vez, continuava o pai dele. Com as diversidades e dificuldades encontradas no Sertão na época da seca na segunda metade do século $X X$, seus produtos desenvolvidos como um espelho do que fazia seu pai, não exerciam mais o poder de venda. Não pela qualidade na confecção ou matéria-prima, pois eram consideradas muito bem feitas e de bom gosto pelos moradores locais, mas pela falta de clientes na localidade de Nova Olinda, Sertão do Cariri-Ce. Sua clientela principal era constituída de vaqueiros, tropeiros e jagunços. Com a falta de chuva, a maioria deles migrou para os grandes centros urbanos, mudando o contexto capitalista de ambos os locais: o Sertão e as cidades. Realidade esta relatada no inicio desse artigo, como uma constante na colonização do território nordestino.

Tendo que sobreviver e alimentar os filhos ainda pequenos, 0 artesão colocava sua produção em sacolas e ia com a mulher D. Francisca, às 4 da manhã para as feiras próximas, tentar vende-los. D. Francisca voltava sempre antes, a pé, para cuidar dos pequenos. Espedito acabava passando por um preço bem mais baixo do valor de mercado, para não voltar de mãos vazias. Mesmo com todas as dificuldades, não queria deixar de trabalhar com a matéria-prima da família, 'couro', mas, pensava em diferenciar o produto tradicional na expectativa de melhorar economicamente.

A oportunidade ocorreu quando Alemberg Quindins, hoje diretor da Fundação Casa Grande (Centro Cultural de Nova Olinda), apareceu em sua oficina perguntando se seria capaz de confeccionar para ele uma réplica da sandália usada por Lampião (Rei do Cangaço). O artesão Espedito puxando pela memória, lembrou que seu pai já havia feito uma sandália para uma pessoa com este nome.

Procurando em seus pertences, encontrou em uma pequena maleta deixada por seu pai antes de morrer com um molde de sandália e algumas ferramentas. Confeccionou a sandália para Alemberg e como foi muito elogiado por todos, viu ai a oportunidade para mudar o estilo que tanto desejava. Esse processo de mudança em seu trabalho artesanal, vivido pelo 
artesão, é justificado seguindo a autora Berta et al (1983, p.50), quando ela considera que:

O artesanato é visto como uma forma de produção em que os trabalhadores desenvolvem uma forma de relação com o objeto de seu trabalho individualizado. E que a construção do produto depende de sua capacidade e de seus conhecimentos para ser criado. $O$ trabalhador das formas de produção artesanal necessita de um aprendizado que não é obtido na escola, mas na relação com o próprio trabalho.

Figura 2: Sandália feita por Espedito Seleiro como versão para a usada por Lampião com solado quadrado.

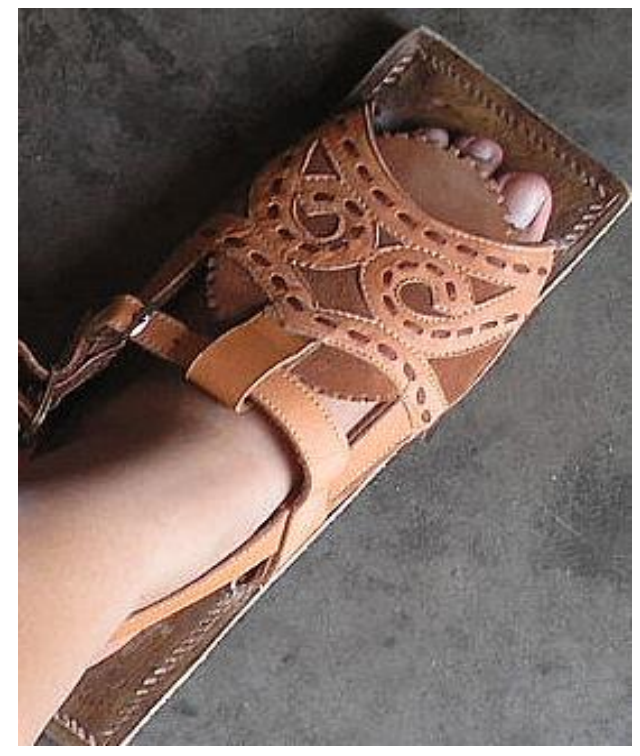

Fonte: Acervo do facebook do artesão Espedito Seleiro.

Alemberg Quindins como é um homem com muitos conhecidos, tratou de divulgar o calçado onde pode. Isso rendeu ao artesão diversos pedidos e uma oportunidade de melhorar de vida. A partir desse calçado de solado quadrado que usava o famigerado Cangaceiro para driblar a policia no Sertão, o artesão começou a desenvolver outras versões da sandália de Lampião, com solados mais comuns, mas com cores diferentes e motivos inspirados nas roupas dos vaqueiros. Com o sucesso da sandália masculina, Seleiro resolveu criar a versão feminina Maria Bonita, considerada até hoje como uma das principais peças de seu trabalho. Desenvolveu bolsas, sacolas de viajem, cintos e outros calçados, entretanto, sempre utilizando a referencia 'vaqueiros' em todas as peças. 
O artesanato associado ao estilo de vida das pessoas e da história desempenha um papel importante na preservação do patrimônio cultural e riqueza da arte tradicional. Segue nas figuras abaixo algumas das peças do artesão Seleiro.

Figura 3: Outras variações da sandália masculina versão Lampião feita por Espedito Seleiro.
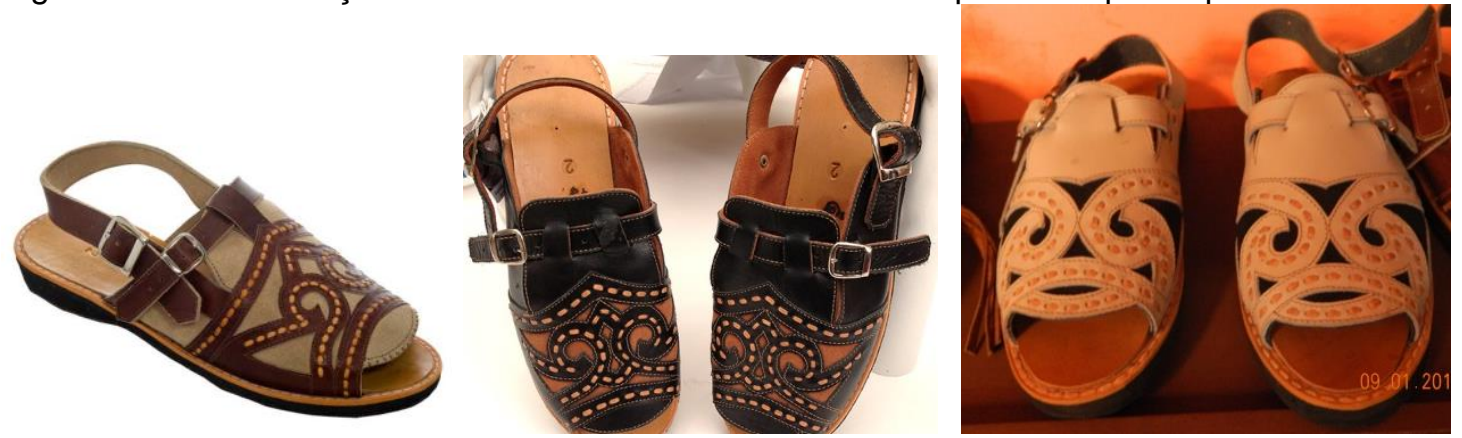

Fonte: Acervo da autora

Figura 4: Sandália feminina Maria Bonita e mochila.
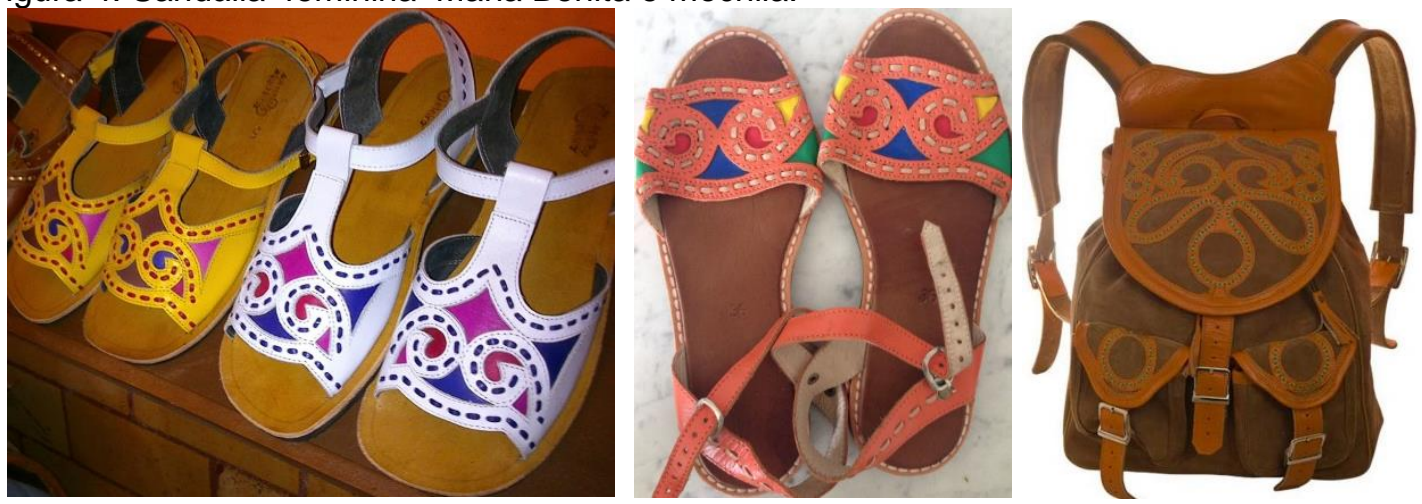

Fonte: Acervo da autora

\section{A CONSTRUÇÃO DE UMA NOVA REALIDADE}

Com o sucesso de suas novas peças, tudo mudou na vida do artesão Espedito Seleiro. Saiu do espaço alugado que ocupou durante 26 anos para seu próprio, em que montou sua nova pequena oficina e sua casa. Hoje tem também uma loja no mesmo local, em que pode-se observar a interessante decoração com elementos da cultura regional, cores fortes e painéis com fotografias de visitantes ilustres, como artistas globais e músicos, além de amigos e pesquisadores. 
Outro fato relevante que impulsionou o nome do artesão na mídia foi à visita da grife Cavalera a cidade em 2006. Eles procuravam pela região acessórios diferentes para incluir no desfile e assim, descobriram o artesão Seleiro. Suas peças participaram do desfile da Cavalera no SPFW ${ }^{9}$ em 2006. A partir daqui os convites não pararam mais. Teve participação também no desfile da grife Cantão e confeccionou o gibão para Marcos Palmeira usar no filme "O homem que desafiou o diabo" em 2007. Em 2008 foi diplomado "Tesouro Vivo" e seu nome inscrito no registro dos mestres da cultura tradicional popular. Participou de vários eventos na área da moda e artesanato e em 2011 foi agraciado com a medalha de Ordem do Mérito cultural do Ministério da Cultura.

\section{CONSIDERAÇÕES FINAIS}

Mesmo com todas as ações de combate as secas desenvolvidas pelos governos, muitos estados do Nordeste, até hoje, passam pelas experiências e dificuldades causadas pelas fases de seca. Muitos sertanejos vão embora de suas terras, mas outros ficam e tentam driblar os obstáculos com perseverança, paciência, força de vontade, habilidade e criatividade. Características essas, que atrelada à confecção de produtos artesanais, traduzem a riqueza e identidade de sua cultura. E quando essa riqueza e identidade são aliados a humildade e simpatia de seu povo, além dos interesses turísticos, atraem admiradores de todos os lugares do mundo. Como foi o caso do artesão Espedito Seleiro.

O artesanato é um setor da economia cujo crescimento possui alto potencial de geração de trabalho e renda. Estimular à preservação das culturas locais, resgatando as vocações regionais, materializa a alma da cultura nordestina.

Um bom programa politico de desenvolvimento desse artesanato, associado a projetos sociais, à formação de uma mentalidade empreendedora, com cursos de capacitação e qualidade e associada ao desenvolvimento turístico, podem ser determinantes para a cidade, para a vida desse sertanejo e para a aceitação deste produto artesanal no mercado interno e externo. 


\section{REFERÊNCIAS}

ALEGRE, Silvia Porto. Mãos de Mestre: Itinerários da arte e da tradição. São Paulo: Maltese, 1994.

BERTA, G. Ribeiro, et al. O artesão tradicional e seu papel na sociedade contemporânea. Rio de Janeiro: Funarte, 1983.

COUTO FILHO, Cândido. Ceará: a civilização do couro. Fortaleza: Edição do autor, 2000.

CUNHA, Euclides da. Os Sertões. , 12ª edição, São Paulo: Três, 1984.

LAVER, James. A Roupa e a moda: uma história concisa. [1. ed.] São Paulo, SP: Companhia das Letras, 2001.285p

ORTIZ, Renato. Cultura Brasileira e Identidade Nacional. São Paulo: Ed. Brasiliense, 5ed, 1994.

PONTES, Antônio Barroso. Sertão Brabo: Usos e costumes. João Pessoa: Secretaria da Educação, 1979.

VILLA, Marco Antonio. Vida e morte no Sertão: História das secas no Nordeste nos séculos XIX e XX. 1a edição, São Paulo: Ed. Ática, 2000.

IBGE. [Documento eletrônico]. Disponível: <http://www.valor.com.br/brasil/2919914/pais-ainda-tem-442-milhoes-detrabalhadores-informais-estima-o-ibge>. Acesso em: 05, julho. 2014.

Exposição Vaqueiros de Andreas Heiniger . Disponivel: <http://www.modasemfrescura.com.br/tag/vaqueiros/>. Acesso em: 05, julho. 2014.

Facebook Espedito Seleiro. Disponível: $<$ https://www.facebook.com/espedito.seleiro?fref=ts>. Acesso em: 05, julho.

\footnotetext{
${ }^{1}$ Valeska Alecsandra de Souza Zuim. Mestranda do programa de Pós-Graduação em Têxtil e Moda da Universidade de São Paulo - USP / BOLSISTA CAPES. Professora da Universidade de Fortaleza - UNIFOR. Valeskazuim@usp.br

${ }^{2}$ Ana Cláudia Silva Farias. Mestranda da Pós-Graduação em Têxtil e Moda da Universidade de São Paulo - USP / BOSISTA CAPES. Professora da Universidade de Fortaleza - UNIFOR. claudiafarias@usp.br

${ }^{3}$ Ana Fabiola Pedrosa de Vasconcelos. Mestranda da Universidade de São Paulo - USP. anafabiolapedrosa@usp.br

${ }^{4}$ Maria Silvia Barros de Held. Professora Doutora da Universidade de São Paulo - USP no curso de Têxtil e Moda. silvaheld.usp@gmail.com
} 
${ }^{5}$ Antônio Takao Kanamaru. Professor Doutor da Universidade de São Paulo - USP no curso de Têxtil de Moda. kanamaru@usp.br

${ }^{6}$ IBGE - Instituto Brasileiro de Geografia e Estatística.

${ }^{7}$ Seleiro - Artesão que fabrica ou conserta selas.

${ }^{8}$ Retirante - Sertanejo nordestino que isolado ou em grupo, emigra fugindo das secas.

9 SPFW (São Paulo Fashion Week)

RECEBIDO EM: agosto/2014

APROVADO EM: agosto/2014 